The authors reported no conflicts of interest.

The Journal policy requires editors and reviewers to disclose conflicts of interest and to decline handling or reviewing manuscripts for which they may have a conflict of interest. The editors and reviewers of this article have no conflicts of interest.

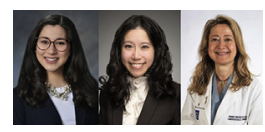

\section{THE STATUS OF} CARDIOTHORACIC SURGERY TRAINEE EDUCATION AND

\section{RECRUITMENT: AN UPDATE ONE YEAR INTO THE CORONAVIRUS DISEASE 2019 (COVID-19) PANDEMIC}

\section{To the Editor:}

One year after our Young Surgeon's Note ${ }^{1}$ was published, we now provide an update on the cardiothoracic (CT) surgery trainee experience later during the novel coronavirus disease 2019 (COVID-19) pandemic. Here, we review new data and best practices regarding trainee education and recruitment.

In mid-2020, multiple studies demonstrated a $25 \%$ to $50 \%$ reduction in trainee case $\operatorname{logs}$ as the primary surgeon. ${ }^{2,3}$ It is highly encouraging that educators in our field recognize these gaps in technical training. During the 2021 General Session of the Thoracic Surgery Directors Association meeting, members discussed methods to assist in the remediation of individual residents, as the group recognized that the pandemic exacerbated challenges related to stress management and team communication. Upcoming Thoracic Surgery Directors Association faculty development webinars aim to assist faculty in mitigating trainee burnout and becoming better operating room instructors. Expanding adjuncts to technical training has also been suggested. Technical competency and autonomy are strengthened by first breaking down cases into fundamental components and then advancing residents on an individual basis. Many residents have thus adapted their practice

\footnotetext{
The Editor welcomes submissions for possible publication in the Letters to the Editor section that consist of commentary on an article published in the Journal or other relevant issues. Authors should: • Include no more than 500 words of text, three authors, and five references. • Type with double-spacing. • See http://jtcs.ctsnetjournals.org/ misc/ifora.shtml for detailed submission instructions. • Submit the letter electronically via jtcvs.editorialmanager.com. Letters commenting on an article published in the JTCVS will be considered if they are received within 6 weeks of the time the article was published. Authors of the article being commented on will be given an opportunity of offer a timely response ( 2 weeks) to the letter. Authors of letters will be notified that the letter has been received. Unpublished letters cannot be returned.

Copyright (c) 2021 The Author(s). Published by Elsevier Inc. on behalf of The American Association for Thoracic Surgery. This is an open access article under the CC BY-NC-ND license (http://creativecommons.org/licenses/by-nc-nd/4.0/).
}

techniques by enhancing the quality and utility of at-home simulators, which incorporate this modular concept of training and graduated complexity. ${ }^{4}$ These simulators are an important adjunct in phase 2 and the postpandemic era due to low cost and ease of assembly.

In addition, the pandemic significantly affected aspiring CT surgeons during elective clerkships and the recruitment process. In April 2021, the Association of American Medical Colleges recommended that away rotations resume because of the vaccination status of medical students; the first rotation block concludes in July 2021 or later with a maximum of one rotation per learner, per specialty. Although this opportunity will potentially help in assessing applicant and program fit, we hope programs continue to offer virtual subinternships and to engage applicants on social media in showcasing their CT surgery programs year-round. Specialty groups should continue to collaborate in crowdsourcing educational and informational materials.

Regarding interviews, in a survey of 2019-2020 CT surgery fellowship applicants, $96 \%$ favored an in-person component to interviews on the basis of increased familiarity with culture/personality and perception of successfully matching. ${ }^{5}$ For the integrated CT surgery residency match, conveying a program's unique strengths and vision for the trajectory of its residents is paramount to best informing applicants who are on the cusp of a 6- or 8-year commitment. Moving forward, we predict that a hybrid approach to recruitment may become the new norm. Potential solutions, although not universally accepted, include offering initial virtual interviews with the choice of either an in-person or virtual second visit. We suggest that applicants remain flexible and programs recognize that hybrid in-person options may disproportionately affect trainees who are juggling financial, job-related, and other personal stressors. The pandemic has not only elucidated pre-existing barriers to education and recruitment but also forced us to implement solutions that ensure a sustainable future for our profession in times of adversity.

Jacqueline K. Olive, $M D^{a}$ Jessica G. Y. Luc, $M D^{b}$

Ourania A. Preventza, $M D, M B A^{c, d}$ ${ }^{a}$ School of Medicine Baylor College of Medicine Houston, Tex

${ }^{b}$ Division of Cardiovascular Surgery Department of Surgery University of British Columbia Vancouver, British Columbia, Canada

${ }^{c}$ Division of Cardiothoracic Surgery Michael E. DeBakey Department of Surgery Baylor College of Medicine Houston, Tex 
${ }^{d}$ Department of Cardiovascular Surgery

Texas Heart Institute

Houston, Tex

\section{References}

1. Olive JK, Luc JGY, Cerqueira RJ, Eulert-Grehn JJ, Han JJ, Phan K, et al. The cardiothoracic surgery trainee experience during the coronavirus disease 2019 (COVID-19) pandemic: global insights and opportunities for ongoing engagement. J Thorac Cardiovasc Surg. 2020;161:178-83.

2. Caruana EJ, Patel A, Kendall S, Rathinam S. Impact of coronavirus 2019 (COVID19) on training and well-being in subspecialty surgery: a National Survey of
Cardiothoracic Trainees in the United Kingdom. J Thorac Cardiovasc Surg. 2020;160:980-7.

3. Purdy AC, de Virgilio C, Kaji AH, Shields Frey E, Lee-Kong S, Inaba K, et al. Factors associated with general surgery residents' operative experience during the COVID-19 pandemic. JAMA Surg. 2021;156:767-74.

4. Kelly JJ, Han JJ, Patrick WL, Mays JC, Iyengar A, Helmers MR, et al. Do-it-yourself simulators and building a culture of practice in the virtual era. J Thorac Cardiovasc Surg Tech. 2021;8:100-11.

5. Taylor M, Wallen T, Mehaffey JH, Shirafkan A, Brescia A, Freeman K, et al Interviews during the pandemic: a Thoracic Education Cooperative Group and surgery residents project. Ann Thorac Surg. March 25, 2021 [Epub ahead of print].

https://doi.org/10.1016/j.xjon.2021.07.035 